\title{
Proteomic patterns analysis with multivariate calculations as a promising tool for prompt differentiation of early stage lung tissue with cancer and unchanged tissue material
}

Piotr Waloszczyk ${ }^{1}$, Tomasz Janus ${ }^{1 *}$, Jacek Alchimowicz ${ }^{2}$, Tomasz Grodzki ${ }^{2}$, Krzysztof Borowiak ${ }^{1}$

\begin{abstract}
Background: Lung cancer diagnosis in tissue material with commonly used histological techniques is sometimes inconvenient and in a number of cases leads to ambiguous conclusions. Frequently advanced immunostaining techniques have to be employed, yet they are both time consuming and limited. In this study a proteomic approach is presented which may help provide unambiguous pathologic diagnosis of tissue material.

Methods: Lung tissue material found to be pathologically changed was prepared to isolate proteome with fast and non selective procedure. Isolated peptides and proteins in ranging from 3.5 to $20 \mathrm{kDa}$ were analysed directly using high resolution mass spectrometer (MALDI-TOF/TOF) with sinapic acid as a matrix. Recorded complex spectra of a single run were then analyzed with multivariate statistical analysis algorithms (principle component analysis, classification methods). In the applied protocol we focused on obtaining the spectra richest in protein signals constituting a pattern of change within the sample containing detailed information about its protein composition. Advanced statistical methods were to indicate differences between examined groups.

Results: Obtained results indicate changes in proteome profiles of changed tissues in comparison to physiologically unchanged material (control group) which were reflected in the result of principle component analysis (PCA). Points representing spectra of control group were located in different areas of multidimensional space and were less diffused in comparison to cancer tissues. Three different classification algorithms showed recognition capability of $100 \%$ regarding classification of examined material into an appropriate group.

Conclusion: The application of the presented protocol and method enabled finding pathological changes in tissue material regardless of localization and size of abnormalities in the sample volume. Proteomic profile as a complex, rich in signals spectrum of proteins can be expressed as a single point in multidimensional space and than analysed using advanced statistical methods. This approach seems to provide more precise information about a pathology and may be considered in futer evaluation of biomarkers for clinical applications in different pathology. Multiparameter statistical methods may be helpful in elucidation of newly expressed sensitive biomarkers defined as many factors "in one point".
\end{abstract}

\footnotetext{
* Correspondence: tjanus@sci.pam.szczecin.pl

'Department of Toxicology and Molecular Pathobiochemistry, Pomeranian

Medical University, 70-204 Szczecin, Poland

Full list of author information is available at the end of the article
} 


\section{Background}

Cancer diagnosis based on standard histological methods is widely described and used in medicine. However, most of the procedures derive from a subjective assessment of observed changes and in some cases may be inconclusive. In practical terms, new, objective methods in cancer diagnosis are still needed especially in respect of their sensitive. Moreover, tumour growth in its early stages is restricted to only a part of the tissue and in some cases it may be overlooked. Recently, proteomics has proved to be a valuable approach in biomarker detection and finding sensitive parameters which indicate disease process [1-4]. The combination of spectroscopic methods of high resolution (mass spectroscopy, nuclear magnetic resonance) with advanced statistical methods leads to an increased likelihood of developing new applications for diagnostic purposes [5-9]. Molecular imaging techniques described in literature as well as profiling and detailed characterisation of biomarker methods tend to prove their usefulness [10-12]. However, many protocols while focusing on details and theoretical aspects, do not translate directly into practical applications since a large number of samples need to be tested to validate them. Molecular imaging with mass spectrometry may offer ample possibilities in practical usage yet in the future rather than at present, because of extent of time necessary for analysis, workload of instruments, and poor image resolution in comparison to other methods [13-15].

Our work suggests an option of proteomic profiling of biological materials which focuses on obtaining spectra rich in proteins that may reveal the proteomic composition of tissue. Using multivariate statistical methods each complex spectrum can be shown as a single point in multidimensional space (as a single parameter), then analysed in respect of localization in this space. The single point in multidimensional space become a specific biomarker if its location does not match the control region. Even a slight change in tissue structure and the nature of pathology of any origin should be reflected in proteomic profile, provided that profiles richest in functional proteome of mass range of $3.5-20 \mathrm{kDa}$ (without high abundant proteins - large proteins) are obtained. These profiles may correspond to a type of the pathological change (cancer, inflammation) as well as to normal profiles. The obtained profiles form something like a "proteomic fingerprint" and allow for classification of tested materials into appropriate groups using statistical methods. Tissue models have to be built for a known lung tissue structure (normal, changed: cancer, inflammation) using supervised classification methods. These methods indicate also signals typical for both normal and pathological tissue (table 1). Once appropriate models are calculated, any unknown lung tissue material can be measured and classified into defined groups (previously built models). The appearance of signals typical for a pathology results in classification of examined tissue into an appropriate model. This appears to be a simple protocol without complex, time consuming and expensive procedures which seems to be relevant considering a large number of samples needed for future models validation.

\section{Methods \\ Materials}

Segments of specimens collected for an intraoperative consultation were examined. Only lung cancer suspected samples were taken into consideration. Diagnosis was made basing on segments prepared with a standard criostatic technique followed by revision on the basis of paraffin method from specimens stained with hematoxilin and eozine (HE) and complemented with immunohistochemical method. Pathological changes in tissues were classified according to The Word Health Organization classification. Types of pathology are listed in table 2 .

All the material for proteomic examination was collected from tissue fragments which did not show necrosis in volume in a macroscopic examination.

The control group (15 different cases) consisted of pathologically unchanged fragments of the lung tissue obtained from lungs removed during surgery on trauma cases. The material did not show any histological changes in histological examination that followed.

\section{Methods}

Mass spectra were recorded in a linear mode of 3.1 $20 \mathrm{kDa}$ with a high resolution mass spectrometer of time of flight type (MALDI-TOF/TOF) Bruker version Autoflex III Smartbeam with $200 \mathrm{~Hz}$ laser technology. Sinapic acid (SA) of proteomic grade (Bruker) was used as a matrix. $400 \mathrm{mg}$ of lung tissue was directly frozen at $-80^{\circ} \mathrm{C}$. Next, just before measurement, the material was defrozen, homogenized with $0.7 \mathrm{ml} 0.9 \% \mathrm{NaCl}$ solution and centrifuged at $13,000 \mathrm{rpm}$ for 10 minutes. The obtained supernatant of $0.6 \mathrm{ml}$ was treated with $50 \mu \mathrm{l}$ of $10 \%$ trifluoracetic acid (TFA) and centrifuged again and then it was transferred to Amicon Ultracel (Millipore) centrifugal filter of $3 \mathrm{kDa}$ selectivity and centifuged at $13,000 \mathrm{rpm}$ to decrease the volume to $50 \mu \mathrm{l}$. The concentrated solution containing proteins and peptides was desalted by twice repeated centrifugation in the same conditions with $450 \mu \mathrm{l}$ of deionized water. Concentrated and desalted material of $10 \mu \mathrm{l}$ was transferred to a conical tube and gently mixed with $20 \mu \mathrm{l}$ of saturated SA (SA in water with $0.1 \%$ TFA and acetonitryl with $0.1 \%$ TFA at a ratio of 60:40). The obtained mixture was 
Table 1 Peak statistics - comparison of statistically important ( $p$ value of T-test/ANOVA < 0.05$)$ peaks for data separation and recognition capability (biomarkers candidates)

\begin{tabular}{|c|c|c|c|c|c|}
\hline Mass $(\mathrm{Da})$ & Mean (Control) & Mean (Pathological) & $\mathrm{P}$ value T-Test/ANOVA & $\mathrm{P}$ value Wilcoxon/Kruskal-Wallis & Difference Average \\
\hline 8616.14 & 0.32 & 1.45 & $<0.000001$ & 0.00000847 & $<0.000001$ \\
\hline 6228.05 & 1.55 & 4.07 & $<0.000001$ & 0.00152 & $<0.000001$ \\
\hline 5759.35 & 1.54 & 2.65 & $<0.000001$ & 0.00017 & 0.000773 \\
\hline 3588.09 & 1.99 & 4.82 & $<0.000001$ & 0.00017 & $<0.000001$ \\
\hline 7596.85 & 0.81 & 2.11 & $<0.000001$ & 0.00154 & $<0.000001$ \\
\hline 5201.26 & 1.93 & 3.87 & $<0.000001$ & 0.000366 & $<0.000001$ \\
\hline 4156.39 & 2.08 & 4.87 & $<0.000001$ & 0.00017 & 0.0000021 \\
\hline 9554.61 & 0.78 & 1.99 & 0.00000228 & 0.11 & $<0.000001$ \\
\hline 12350.75 & 0.25 & 1.22 & 0.00000228 & 0.0000289 & $<0.000001$ \\
\hline 3603.83 & 2.11 & 4.11 & 0.0000024 & 0.0162 & $<0.000001$ \\
\hline 6723.40 & 20.93 & 8.96 & 0.00000228 & 0.00000855 & 0.000101 \\
\hline 11297.49 & 0.45 & 0.97 & 0.00000228 & 0.00807 & $<0.000001$ \\
\hline 10268.09 & 0.59 & 1.56 & 0.00000341 & 0.000314 & $<0.000001$ \\
\hline 10525.25 & 0.3 & 1.19 & 0.00000695 & 0.00017 & $<0.000001$ \\
\hline 5800.39 & 1.79 & 3.82 & 0.00000122 & 0.195 & $<0.000001$ \\
\hline 5910.05 & 1.78 & 3.59 & 0.00000596 & 0.00375 & $<0.000001$ \\
\hline 10403.69 & 0.47 & 1.43 & 0.000225 & 0.000331 & $<0.000001$ \\
\hline 8297.66 & 0.95 & 1.62 & 0.000225 & 0.176 & $<0.000001$ \\
\hline 4570.52 & 4.96 & 7.49 & 0.000296 & 0.106 & $<0.000001$ \\
\hline 9440.24 & 0.71 & 1.08 & 0.000296 & 0.11 & $<0.000001$ \\
\hline 6656.68 & 6.27 & 2.07 & 0.000608 & 0.00000986 & $<0.000001$ \\
\hline 11325.26 & 0.67 & 1.09 & 0.00168 & 0.488 & $<0.000001$ \\
\hline 9172.09 & 34.55 & 12.13 & 0.00171 & 0.00017 & $<0.000001$ \\
\hline 7042.18 & 23.45 & 5.42 & 0.00252 & 0.0000902 & $<0.000001$ \\
\hline 6020.90 & 5.33 & 2.28 & 0.00252 & 0.00017 & $<0.000001$ \\
\hline 11185.69 & 0.75 & 1.19 & 0.00252 & 0.891 & $<0.000001$ \\
\hline 4995.04 & 2.28 & 3.87 & 0.00409 & 0.162 & $<0.000001$ \\
\hline 8456.35 & 1.25 & 2.82 & 0.00517 & 0.31 & $<0.000001$ \\
\hline 9960.78 & 0.78 & 1.82 & 0.0059 & 0.211 & $<0.000001$ \\
\hline 7283.97 & 39.59 & 7.2 & 0.00715 & 0.000151 & $<0.000001$ \\
\hline 7249.02 & 2.69 & 1.77 & 0.00757 & 0.0042 & 0.00064 \\
\hline 7173.62 & 4.21 & 7.46 & 0.00935 & 0.647 & $<0.000001$ \\
\hline 5711.21 & 4.23 & 6.21 & 0.00935 & 0.441 & $<0.000001$ \\
\hline 9378.33 & 1.82 & 1 & 0.00935 & 0.00238 & $<0.000001$ \\
\hline 4048.24 & 4.11 & 7.16 & 0.0141 & 0.176 & $<0.000001$ \\
\hline 5837.80 & 2.19 & 3.04 & 0.0197 & 0.423 & $<0.000001$ \\
\hline 3907.34 & 41.93 & 14.71 & 0.021 & 0.00771 & $<0.000001$ \\
\hline 10840.50 & 0.99 & 2.24 & 0.0231 & 0.149 & 0 \\
\hline 6745.30 & 2.08 & 1.56 & 0.0392 & 0.0221 & 0.00817 \\
\hline
\end{tabular}

directly applied onto standard steel target and analyzed following solvent evaporation.

The instrument operated under control of FlexControl software (Bruker).

All the statistical calculations were done using ClinProtTols ver. 2.2 software (Bruker). Proteomic profiles were analyzed with principle component analysis algorithm (PCA) to observe differences in proteome profiles of particular groups. Supervised classification algorithms, Support Vector Machine (SVM), Genetic Algorithm (GA) and Supervised Neural Network (SNN) were used for classification of tissue signals into appropriate groups. 
Table 2 Types $f$ pathological change diagnosed in examined material

\begin{tabular}{ll}
\hline Diagnosis & Number of cases \\
\hline Squamous cell carcinoma & 25 \\
\hline Adenocarcinoma & 27 \\
\hline Large cell carcinoma & 4 \\
\hline Typical carcinoid & 1 \\
\hline Large cell neuroendocrine carcinoma & 3 \\
\hline Small cell carcinoma & 2 \\
\hline Adenosquamous carcinoma & 4 \\
\hline Sarconiatoid carcinoma & 4 \\
\hline Bening tumors & 2 \\
\hline Metastasis & 2 \\
\hline Lymphoma & 2 \\
\hline Ectopic tissue and tumor-like lesions & 9 \\
\hline
\end{tabular}

\section{Results}

MS analysis in 100 (15 control, 85 pathological) tissue isolates was done. Results as combined spectra in gel view mode are shown in figure 1.

All the spectra were analyzed with PCA algorithm and resulting data distribution in three-dimensional space view is presented in figure 2 . Rounded points are the control group profiles and are marked for reasons of clarity.

Statistical analysis of all profiles for biomarker discovery revealed 39 masses of statistical importance $(p<0.005)$ which influenced division of investigated groups. Results are listed in table 1.

Proteome profiles were classified using three different supervised algorithms. Data for both (X1 - control, X2 pathological) and recognition capability are listed in table 3.

\section{Discussion}

The proteomic investigation as a novel technique for biomarker discovery in disease process requires application of dedicated solutions including both advanced instruments and software. However, separation and concentration procedure are crucial for protein analysis [16]. Proteins of interest are a minority in comparison to a huge number of large structural proteins and other compounds which may negatively influence identification process especially in complex biological materials (blood, tissue) [17]. Moreover, mass spectroscopy with matrix associated laser desorption ionization, has its limitations: lack of highly abundant proteins in a sample, lack of salts, need for appropriate analytic concentrations, etc [18]. A number of protocols are described in literature for separation, concentration and desalting of proteins, however most of them are costly and time consuming [19-21]. We found that for peptides/proteins profiles purposes, considering the nature (composition structure) of materials, it was enough to isolate only a limited range of proteins which could be presented as a single point in multidimensional space basic on

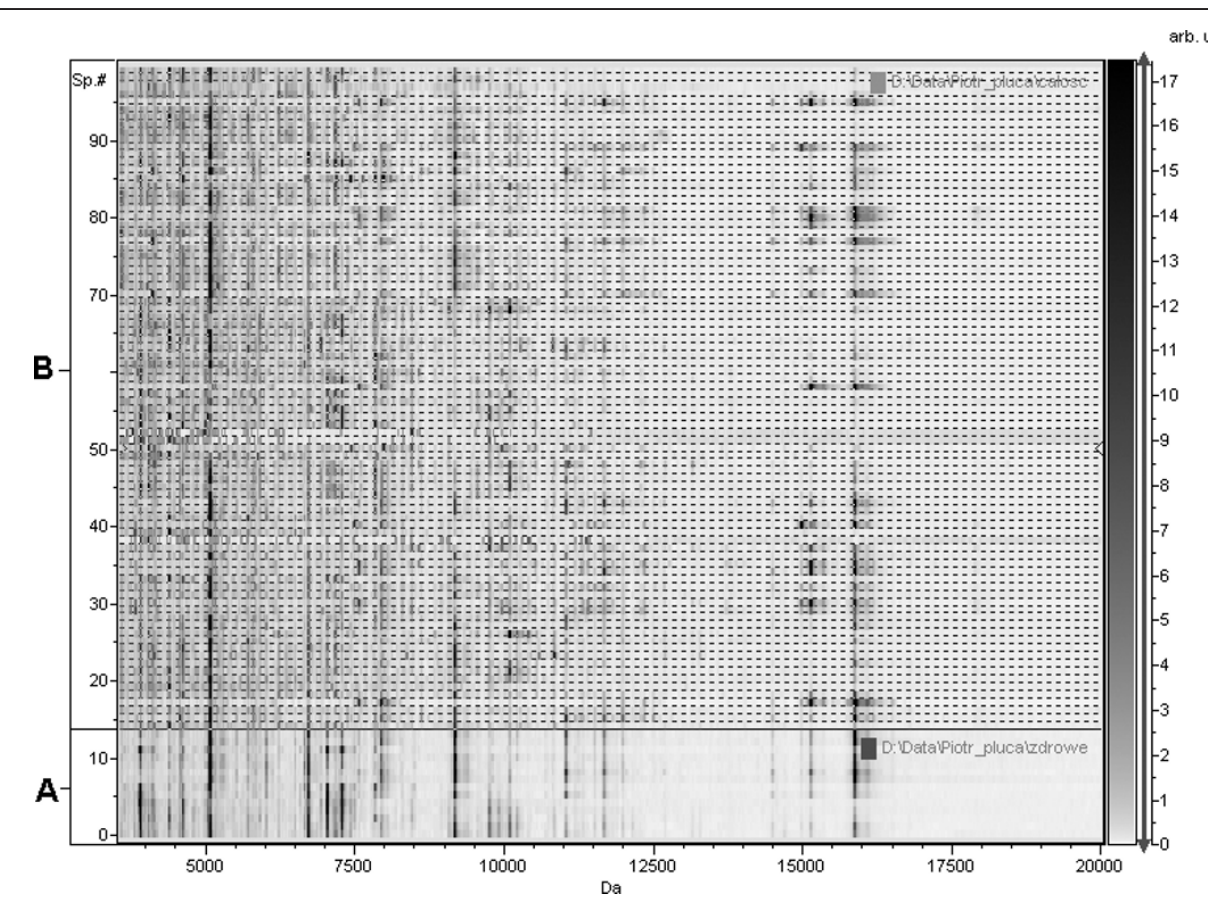

Figure 1 MS spectra in gel view mode: a) control group, b) pathologically changed tissues 


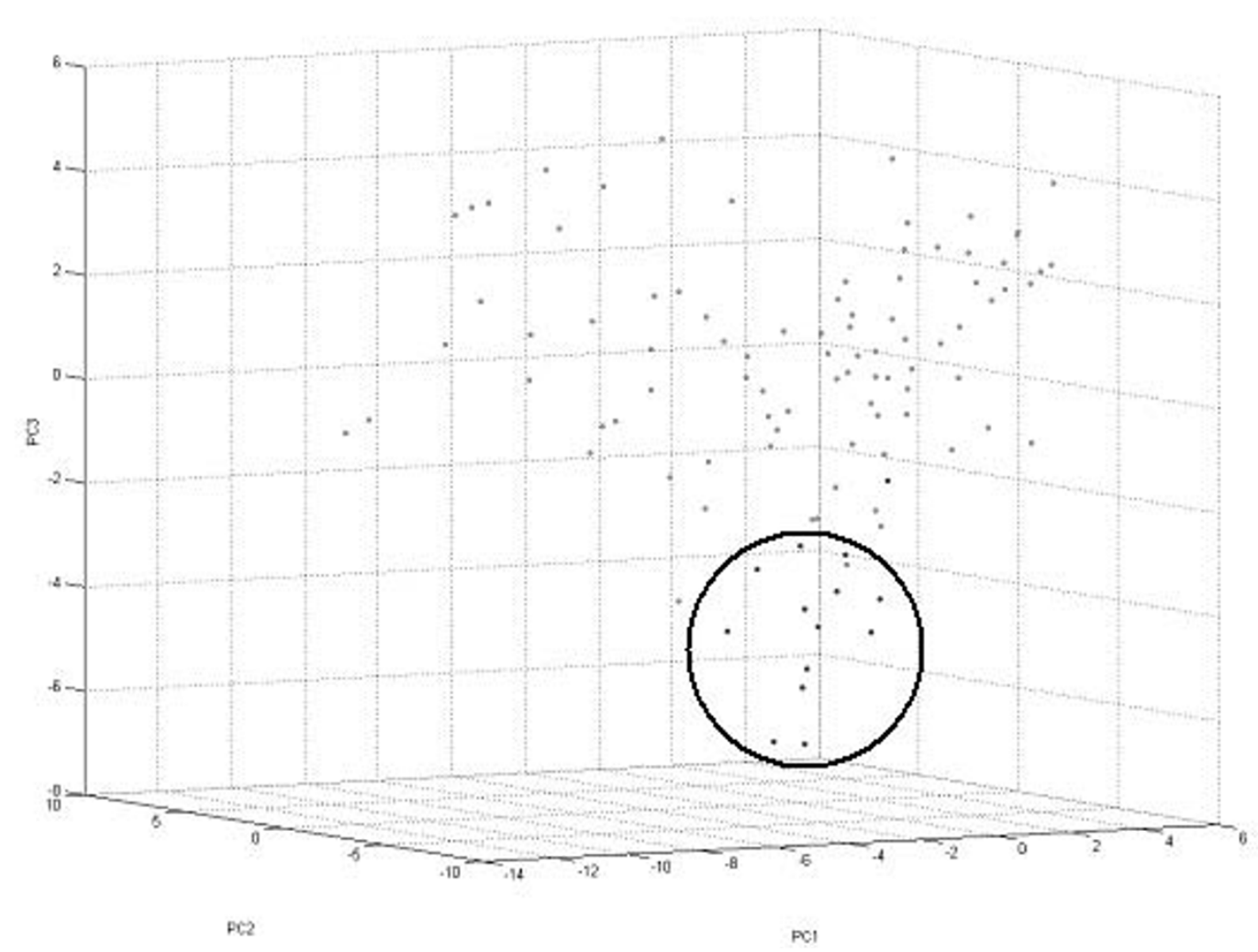

Figure 2 The result of principle component analysis (PCA). Data distribution in three-dimensional space (PC1 - PC2- PC3). Points of control group were rounded.

statistical methods. A large number of mass signals recorded during measurement merge into one "signal" (a point located in multidimensional space) which can be treated as a specific biomarker. The obtained profiles (single points) become characteristic "fingerprints" for tissue composition. Any pathological changes in the examined material result in different localization in comparison to unchanged material what can be easy seen. Depending on the extent of pathological changes in tissue structure, proteins isolation procedure should include either more or fewer separation steps to obtain fractions which then can be successfully analyzed separately. In our approach we performed a simple isolation procedure based on precipitation of large proteins and

Table 3 Classification results

\begin{tabular}{|c|c|c|c|c|}
\hline \multirow[t]{2}{*}{ Algorithm } & \multicolumn{3}{|c|}{ Validation } & \multirow{2}{*}{$\begin{array}{l}\text { Recognition } \\
\text { capability }\end{array}$} \\
\hline & XVal & $\mathrm{X} 1$ & $\mathrm{X} 2$ & \\
\hline $\begin{array}{l}\text { Support Vector Machine } \\
\text { (SVM) }\end{array}$ & $95.8 \%$ & $98.8 \%$ & $92.9 \%$ & $100 \%$ \\
\hline Genetic Algorithm (GE) & $95.3 \%$ & $97.7 \%$ & $92.9 \%$ & $100 \%$ \\
\hline $\begin{array}{l}\text { Supervised Neural Network } \\
\text { (SNN) }\end{array}$ & $88.7 \%$ & $98.8 \%$ & $78.6 \%$ & $100 \%$ \\
\hline
\end{tabular}

then filtration using filters of cut-off level $3 \mathrm{kDa}$ to concentrate and desalt peptides/proteins. This procedure allowed us to collect proteins in such a form that they can be measured directly in spectrometer without any expensive and time consuming procedures. As a detail examination of structure of particular peptides/proteins differentiating points distribution in multidimensional space was not our intent, we focused on reproducibility of this procedure. Our aim was to analyse profiles and compare them rather then to analyse a particular compound of which the profile was composed. Figure 1 presents spectra of all 100 samples, including control tissues (A) and pathologically changed (B) in gel view mode in order to combine all of them in one Figure 1. The data combination reveals that common signals may be noted in broad spectrum for both groups but pathological samples are even more complex in ranges between common bands. Signals in the same masses are most likely typical for the tissue origin (lung) and they reflect common to some extend structure for both types of the same tissues (pathological and normal). The multivariate statistical method enabled to distinguish normal samples from those diagnosed with cancer as well as those which indicate other pathological changes (table 2). As we were aware that signals typical for pathological 
tissue may overlap with signals coming from normal tissue which is present in material in every tumour growth in an unchanged form, we decided to examine a relatively large tissue segment of $400 \mathrm{mg}$, covering normal and pathological region. This facilitated testing specificity and sensitivity of the method with view to an early pathological change detection (in case the change cannot be seen macroscopically).

Recorded MS data typically comprise a large number of signals which makes it impossible to tell the difference between examined groups basing on direct raw MS spectra. However, the principle component analysis (PCA) algorithm enables to present complex spectrum in a single point located in multidimensional space. This location is strictly defined by sample composition, and the points representing spectra can be easily compared. The result of PCA analysis of all the samples shown in Figure 2 revealed different localization of normal and pathological samples. Moreover, pathological samples were more dispersed in space which could be explained by the fact that many different types of cancer were examined. We found 39 different masses (table 1) which are of statistical importance and discriminate all the data. The examination of compounds structure is a typical approach and has been widely described in references. We found that as much as 39 masses influence samples distribution in multidimensional space and all of them may be important for change identification. A typical approach based on a single, one-parametrical statistical investigation seems to be less efficient compared to multiparametrical methods especially in respect of sensitivity and selectivity. Also we attempted to point out that there was no need to precisely define (protein structure identification) each of 39 signals because all of them are strictly defined by the point located in multidimensional space (non - dimensional data $\mathrm{x}, \mathrm{y}, \mathrm{z}$ ). Points obtained from PCA calculations can be then classified and compared using different classification algorithms (table 3). In our experiment the recognition capability of the tree most common models was $100 \%$ which may demonstrate a high specificity of the procedure.

\section{Conclusions}

The proteomic investigation of tissue samples using advanced statistical methods enabled differentiation of lung tissue with cancer and unchanged tissue material even in an early stage of growth (low pathologcial to unchanged tissue ratio in sample). Following ist validation, this method, supporting commonly used histological techniques, may be considered an objective, precise and fast procedure in an early cancer diagnosis. Our protocol may be useful in procedures that need a large number of samples due to the elimination of time consuming steps. Multiparameter statistical methods may be helpful in elaboration of newly defined biomarkers for clinical applications expressed as many factors "in one point".

\section{Author details}

'Department of Toxicology and Molecular Pathobiochemistry, Pomeranian Medical University, 70-204 Szczecin, Poland. ${ }^{2}$ Professor A. Sokolowski Specialist Hospital Szczecin Zdunowo, Poland.

\section{Authors' contributions}

PW collected and registered all the samples, performed histological examinations, participated in the design of the study, MS measurements and data analysis, participated in data analysis and interpretation. TJ conceived of the study, developed the methodology, carried out MS measurements, performed the data analysis and interpretation, drafted the manuscript. JA and TG collected segments of specimens and participated in clinical diagnosis. KB participated in design of the study and its coordination. All authors read and approved the final manuscript.

\section{Competing interests}

The authors declare that they have no competing interests.

Received: 27 November 2010 Accepted: 21 March 2011

Published: 21 March 2011

\section{References}

1. Palmblad M, Tiss A, Cramer R: Mass spectrometry in clinical proteomics from the present to the future. Proteomics Clin Appl 2009, 3:6-17.

2. Munro NP, Cairns DA, Clarke P, Rogers M, Stanley AJ, Barrett JH, Harnden P, Thompson D, Eardley I, Banks RE, Knowles MA: Urinary biomarker profiling in transitional cell carcinoma. Int J Cancer 2006, 119:2642-2650.

3. Coombes KR, Morris JS, Hu J, Edmonson SR, Baggerly KA: Serum proteomics profiling - a young technology begins to mature. Nature Biotechnol 2005, 23:291-292.

4. Check E: Proteomics and cancer: running before we can walk. Nature 2004, 429:496-497.

5. Zhang $X$, Leung SM, Morris $C R$, Shigenaga MK: Evaluation of a novel, integrated approach using functionalized magnetic beads, bench-top MALDI-TOF-MS with prestructured sample supports, and pattern recognition software for profiling potential biomarkers in human plasma. J Biomol Technol 2004, 15:167-175.

6. Li J, Zhang Z, Rosenzweig J, Wang YY, Chan DW: Proteomics and bioinformatics approaches for identification of serum biomarkers to detect breast cancer. Clin Chem 2002, 48:1296-1304.

7. Petricoin EF, Ardekani AM, Hitt BA, Levine PJ, Fusaro VA, Steinberg SM, Mills GB, Simone C, Fishman DA, Kohn EC, Liotta LA: Use of proteomic patterns in serum to identify ovarian cancer. Lancet 2002, 359:572.

8. Conrads TP, Zhou M, Petricoin EF, Liotta LA, Veenstra TD: Cancer diagnosis using proteomic patterns. Expert Rev Mol Diagn 2003, 3:411.

9. Aebersold R, Goodlett DR: Mass spectrometry in proteomics. Chem Rev 2001, 101:269-295

10. Stoeckli M, Staab D, Schweitzer A: Compound and metabolite distribution measured by MALDI mass spectrometric imaging in whole-body tissue sections. Int J Mass Spectrom 2007, 260:195-202.

11. Andersson M, Groseclose MR, Deutch AY, Caprioli RM: Imaging mass spectrometry of proteins and peptides: $3 \mathrm{D}$ volume reconstruction. Nat Methods 2008, 5:101-108.

12. Caldwell RL, Caprioli RM: Tissue profiling by mass spectrometry: A review of methodology and applications. Mol Cell Proteomics 2005, 4:394-401.

13. Chaurand P, Norris JL, Cornett DS, Mobley JA, Caprioli RM: New developments in profiling and imaging of proteins from tissue sections by MALDI mass spectrometry. J Proteome Res 2006, 5:2889-2900.

14. Cornett DS, Reyzer ML, Chaurand P, Caprioli RM: MALDI imaging mass spectrometry: Molecular snapshots of biochemical systems. Na Methods 2007, 4:828-833

15. Khatib-Shahidi S, Andersson M, Herman JL, Gillespie TA, Caprioli RM: Direct molecular analysis of whole-body animal tissue sections by imaging MALDI mass spectrometry. Anal Chem 2006, 78:6448-6456. 
16. Rifai N, Gillette MA, Carr SA: Protein biomarker discovery and validation: The long and uncertain path to clinical utility. Nat Biotechnol 2006, 24:971-983.

17. Duncan R, McConkey EH: How many proteins are there in a typical mammalian cell? Clin Chem 1982, 28:749-755.

18. Diamandis EP: Mass spectrometry as a diagnostic and a cancer biomarker discovery tool: opportunities and potential limitations. Mol Cell Proteomics 2004, 3:367-378.

19. Omenn GS: Strategies for plasma proteomic profiling of cancers. Proteomics 2006, 6:5662-5673.

20. Rifai N, Gillette MA, Carr SA: Protein biomarker discovery and validation: The long and uncertain path to clinical utility. Nat Biotechnol 2006, 24:971-983.

21. Görg A, Weiss W, Dunn MJ: Current two-dimensional electrophoresis technology for proteomics. Proteomics 2004, 4:3665-3685.

doi:10.1186/1746-1596-6-22

Cite this article as: Waloszczyk et al: Proteomic patterns analysis with multivariate calculations as a promising tool for prompt differentiation of early stage lung tissue with cancer and unchanged tissue material. Diagnostic Pathology 2011 6:22.

\section{Submit your next manuscript to BioMed Central and take full advantage of:}

- Convenient online submission

- Thorough peer review

- No space constraints or color figure charges

- Immediate publication on acceptance

- Inclusion in PubMed, CAS, Scopus and Google Scholar

- Research which is freely available for redistribution

Submit your manuscript at www.biomedcentral.com/submit 